\title{
Effect of pomegranate extracts on brain antioxidant markers and cholinesterase activity in high fat-high fructose diet induced obesity in rat model
}

\author{
Zahra Amri ${ }^{*}$, Asma Ghorbel ${ }^{2}$, Mouna Turki ${ }^{3}$, Férièle Messadi Akrout ${ }^{2}$, Fatma Ayadi ${ }^{3}$, Abdelfateh Elfeki ${ }^{4}$
} and Mohamed Hammami ${ }^{1}$

\begin{abstract}
Background: To investigate beneficial effects of Pomegranate seeds oil (PSO), leaves (PL), juice (PJ) and (PP) on brain cholinesterase activity, brain oxidative stress and lipid profile in high-fat-high fructose diet (HFD) induced-obese rat.

Methods: In vitro and in vivo cholinesterase activity, brain oxidative status, body and brain weight and plasma lipid profile were measured in control rats, HFD-fed rats and HFD-fed rats treated by PSO, PL, PJ and PP.

Results: In vitro study showed that PSO, PL, PP, PJ inhibited cholinesterase activity in dose dependant manner. PL extract displayed the highest inhibitory activity by $\mathrm{IC} 50$ of $151.85 \mathrm{mg} / \mathrm{ml}$. For in vivo study, HFD regime induced a significant increase of cholinesterase activity in brain by $17.4 \%$ as compared to normal rats. However, the administration of PSO, PL, PJ and PP to HDF-rats decreased cholinesterase activity in brain respectively by $15.48 \%, 6.4 \%, 20 \%$ and $18.7 \%$ as compared to untreated HFD-rats. Moreover, HFD regime caused significant increase in brain stress, brain and body weight, and lipid profile disorders in blood. Furthermore, PSO, PL, PJ and PP modulated lipid profile in blood and prevented accumulation of lipid in brain and body evidenced by the decrease of their weights as compared to untreated HFD-rats. In addition administration of these extract protected brain from stress oxidant, evidenced by the decrease of malondialdehyde (MDA) and Protein carbonylation (PC) levels and the increase in superoxide dismutase (SOD) and glutathione peroxidase (GPx) levels.
\end{abstract}

Conclusion: These findings highlight the neuroprotective effects of pomegranate extracts and one of mechanisms is the inhibition of cholinesterase and the stimulation of antioxidant capacity.

Keywords: Obesity, Brain, Pomegranate, Oxidative stress, Anti-cholinesterase activity

\section{Introduction}

Obesity is widely known as risk factor for diabetes [1], cardiovascular diseases and neurodegenerative diseases [2-4] such as Alzheimer's disease (AD) which is a the most prevalent form of dementia characterized by a progressive decline in memory, behavior, and cognitive functions in the elderly population [5]. Based on current data, regression studies have shown that higher body

\footnotetext{
* Correspondence: zahraamri23@yahoo.fr

1'Biochemistry Laboratory, LR12ES05 "Nutrition- Functional Foods and vascular Health", Faculty of Medicine, University of Monastir, 5019 Monastir, Tunisia

Full list of author information is available at the end of the article
}

mass index (BMI) was associated with decreased brain volume $[6,7]$ and people with higher midlife BMI or central adiposity measures have a two times higher risk of dementia in later life [8-10]. In addition, clinical studies have reported deficits in learning, memory and executive function in obese as compared to non-obese patients [11] and have confirmed alterations and reduction in focal gray matter volume in obese young adults [12]. Moreover, experimental studies have shown that obesity altered brain structure and function and which lead to cognitive deficit $[13,14]$. Indeed, cognitive decline was correlated with degeneration of cholinergic system [15] caused by increasing in cholinesterase activity. Bon fleur et al. 2000 have 
demonstrated that AchE activity was significantly higher in cortex, hypothalamus and total brain samples in monosodium L-glutamate (MSG)-induced obese mice and rats as compared to control [16]. Also Pistell et al. 2010 have reported that High Fat Lard diet increased body weight, impaired cognition and increased brain inflammation [6]. Furthermore, Zhang et al. 2005 have explained that increased oxidative stress as mediator of cells death induces neural oxidative stress and inflammation in rat cerebral cortex [17]. The evident correlation between obesity and dementia prompted researchers to look for healthy diet with high antioxidant impact given that long term use of neurodegenerative diseases drugs can induce adverse side effects that may not be tolerated by patients [18].

More recently, the interest in the role of dietary antioxidants in human health has prompted research in the field of AD [19-21]. In this regard, pomegranate, considered recently as functional food exhibited a variety of healthy effects [22]. In fact, different pomegranate parts have been known as an arsenal of bioactive compounds such as phenolics, anthocyanins, vitamins and minerals $[23,24]$. This richness attributed to them a power antioxidant activity and protective effects against major chronic diseases such as obesity, diabetes, cancer and Alzheimer [1, 25-28]. Several studies have investigated the protective effect of pomegranate parts on different organs such as liver [29-31], heart [32] and skeletal muscle [33] in obese rat model. But till now, there are no studies conducted to find out the effect of long-term pomegranate consumption on oxidative status in brain in obese rat. To fill the information gap, we designed this study to investigate whether consumption of pomegranate parts: oil seeds (PSO), juice (PJ), peel (PP) and leaves (PL) would alleviate oxidative status and cognitive decline in HFD-induced obesity rat model.

\section{Methods \\ Plant materials}

Pomegranate leaves and fruits were harvested from Tounsi trees in October 2015 from Mahdia region, Tunisia. Variety authenticity was confirmed by taxonomist Dr. Faten Zaouay from the Department of Horticulture, Higher Agronomic Institute (University of Sousse, Tunisia) and a voucher specimen was deposited in herbarium at the Faculty of Pharmacy (University of Monastir, Tunisia).

Fruits were washed and hand-peeled. Arils were squeezed using a commercial blender (moulinex, France). The extract juice was centrifuged at $15000 \mathrm{rpm}$ for $15 \mathrm{~min}$. Then the supernatant was recuperated and lyophilized.

The grains were manually separated from the pulp, carefully washed and dried in the sun until constant weight. Then, the grains were crushed and sieved to obtain fine powders. Leaves and peel were sundried and powdered.

\section{Extraction}

Leaves and peel powders were extracted with methanol $50 \mathrm{~g} / 250 \mathrm{ml}$ in the dark for $48 \mathrm{~h}$. Each extract was filtered and evaporated to dryness and stored at $-20{ }^{\circ} \mathrm{C}$ for further determination.

Oil was extracted from pomegranate seeds by the methods of soxhlet. About $30 \mathrm{~g}$ seeds were extracted with $200 \mathrm{ml}$ of hexane at room temperature for $6 \mathrm{~h}$. The solvent was removed by evaporation at $40{ }^{\circ} \mathrm{C}$ and the oil was flushed with nitrogen stream and stored at $-20{ }^{\circ} \mathrm{C}$ in sealed tubes.

\section{In vitro determination of AChE activity}

The AchE assay was performed according to the colorimetric methods of Ellman et al. [34, 35], with some modifications using as a substrate the propionylthiocholine iodide (PTCI), the commonly used substrate for in vitro AChE determinations. Heparinized plasma was prepared from human blood volunteers to use as enzyme source. $100 \mu \mathrm{l}$ of each pomegranate extracts was mixed with an enzyme solution $(100 \mu \mathrm{l})$ and incubated at $37{ }^{\circ} \mathrm{C}$ for $10 \mathrm{mn}$. Absorbance at $405 \mathrm{~nm}$ was read immediately after adding an Ellman's reaction mixture 0.25 mM 5.5 5, 5'-Dithiobis 2-nitrobenzoic acid (DTNB); $7 \mathrm{mM}$ PTCI; $50 \mathrm{mM}$ sodium phosphate buffer $(\mathrm{pH} 7.7)$. The blank reaction was measured by substituting saline for the enzyme. The percentage of AchE inhibition was calculated using the following formula $(1-\mathrm{S} / \mathrm{E}) \times 100$; where $\mathrm{E}$ and $\mathrm{S}$ were the enzyme activities without and with the test sample, respectively. IC50 values were determined from the inhibition percentage values of different concentrations of each plant extract tested in triplicate.

\section{Experimental design}

35 healthy adult male Wistar rats weighing about 200$250 \mathrm{~g}$ were purchased from the central pharmacy of Tunisia (SIPHAT, Tunis City, Tunisia). At arrival, animals were acclimatized for a period of 7 days in environmentally controlled breeding room standard environmental conditions such controlled temperature $\left(22 \pm 2{ }^{\circ} \mathrm{C}\right)$, a 12 $\mathrm{h}$ light/dark cycle and a humidity of $60 \pm 5$. Experimental procedures were approved by Animal Ethics Committee of the University of Sfax (Sfax, Tunisia) for the care and use of laboratory animals.

Animals were divided into 6 groups of 6 animals each and allowed free access to tap water and alimentation during the experimental period. Standard diet was composed by corn, soya and vitamins. High fat-high fructose diet was composed by $69.9 \%$ standard diet, $15 \%$ animal fat, $15 \%$ fructose and $0.1 \%$ cholic acid. The experimental groups were as followed: 
- Control group (CG): rats fed a standard diet and received daily $1 \mathrm{ml}$ of tap water by gavage

- HFD group (HFD): rats fed a high fat-high fructose diet and received daily $1 \mathrm{ml}$ of tap water by gavage

- HFD+ PSO group (HFD+ PSO): rats fed with a high fat-high fructose diet and received pomegranate seeds oil ( $2 \mathrm{ml} / \mathrm{kg}$ of BW daily)

- HFD+ PJ group (HFD+ PJ): rats fed with a high fathigh fructose diet and received pomegranate juice (250 mg/kg of BW daily)

- HFD+ PP group (HFD+ PP): rats fed with a high fat-high fructose diet and received pomegranate peel (250 mg/kg of BW daily)

- HFD+ PL group (HFD+ PL): rats fed with a high fat-high fructose diet and received pomegranate leaves (250 mg/kg of BW daily)

At the end of treatment period (12 weeks), rats were killed by decapitation. Blood was collected and plasma was processed for lipid profile, cholinesterase activity and oxidative stress assessment. Whole brain was carefully dissected, rapidly removed, weighed and homogenized in phosphate buffer $\mathrm{pH} 7.4$ with an ultrathurax homogenizator. After centrifugation at $10000 \mathrm{~g}, 4{ }^{\circ} \mathrm{C}$ for 10 min, supernatant was used for determination of brain enzymes activities: BchE and oxidative stress.

\section{Determination of ChE inhibitory activity in brain}

The BChE inhibitory activity was performed according to the colorimetric method, using butyrylthiocholine as a substrate (CHRONOLAB system). Protein concentration was determined according to the lowry method with bovine serum albumin (BSA), as a protein standard. The rates of hydrolysis by $\mathrm{BChE}$ were monitored spectrophotometrically. $1.5 \mathrm{ml}$ of substrate was mixed with $10 \mu \mathrm{l}$ of enzyme solution (brain homogenate or plasma samples). The yellow reaction product was quantified by reading immediately the absorbance at $405 \mathrm{~nm}$. The reaction was monitored over a period of $1.5 \mathrm{~min}$ with readouts taken every 30s. Quantification of the enzymatic activity was based on a change in optical density in the linear range over time, using the molar extinction coefficient of the reaction products. The spectrophotometric absorption was quantitatively measured and expressed as mole of butyrylcholine hydrolysed $/ \mathrm{mn} / \mathrm{ml}$ plasma or /g cortical tissue protein.

\section{Biochemical plasma analysis}

The levels of total cholesterol (TC), total triglycerides (TG), low density lipoprotein cholesterol (LDL-C) and high density lipoprotein- cholesterol (HDL-C), as well as the activities of Alanine Aminotransferase (ALT) and aspartate aminotransferase (AST) were determined in fasting blood using commercially available kits (Bekman Counter, Galway, Ireland).

\section{Evaluation of brain antioxidant status Determination of malondialdehyde}

Brain lipoperoxidation was evaluated by malondialdehyde (MDA) measurement using thiobarbituric acid reactive substances (TBARS) assay according to the method of [36]. Spectrophotometric measurement was done at $532 \mathrm{~nm}$ and the results were expressed as the amount of nmole of MDA per mg of protein.

\section{Determination of protein carbonylation}

Oxidative damage to proteins was evaluated by quantifying protein carbonylation quantification in brain homogenate according to [37]. Homogenate was incubated with 2, 4, dinitrophenylhydrazine $10 \mathrm{mM}$ DNPH containing buffer for $1 \mathrm{~h}$ at room temperature and then proteins were precipitate with $20 \%(w / v)$ trichloroacetic acid (TCA). After centrifugation at $4000 \mathrm{rpm}$ for $5 \mathrm{mn}$, the supernatant was removed and the precipitate was washed firstly with $10 \%(w / v)$ TCA solution and then by of $1: 1(v / v)$ ethanol: ethyl acetate and finally mixed with $6 \mathrm{M}$ guanidine hydrophilic solution. After vigorous vortex, the mixture was centrifuged at $4000 \mathrm{rpm}$ and the absorbance of the supernatant was measured at $370 \mathrm{~nm}$. The protein carbonyl content was expressed as $\mu \mathrm{M}$.

\section{Determination of superoxide dismutase (SOD)}

Superoxide dismutase (SOD) activity was determined according to the method of [38]. Enzymatic activity is directly proportional to the inhibition rate of nitroblue tetrazolium (NBT) oxidation by $\mathrm{O}_{2}^{-}$anion. The absorbance was measured at $580 \mathrm{~nm}$ and the activity was expressed as U/mg protein in liver and kidneys. One unit of SOD activity was defined as the amount of enzyme that inhibits $50 \%$ of NBT reduction.

\section{Determination of glutathione peroxidase (GPx)}

Glutathione peroxidase (GPx) activity was measured as described by Flohe \& Gunzler [39]. Glutathione (GSH) oxidation by GPx is coupled to the transformation of 5 , 50-dithiobis-(2- nitrobenzoic acid) (DTNB) into 2-nitro5-thiobenzoate (TNB) which absorbs at $412 \mathrm{~nm}$. Enzymatic activity was expressed as $\mathrm{U} / \mathrm{g}$ protein in liver and kidneys.

\section{Statistical analysis}

Results are expressed as means \pm SEM (Standard Error of the Mean) and analyzed using SPSS ver. 21.0, professional edition. A one-way analysis of variance (ANOVA) was then performed and followed by Duncan's test to estimate the significance among the main effects at the $5 \%$ probability level. Significant differences $(P<0.05)$ between means were 
Table 1 IC50 values of AChE inhibitory activity in vitro of pomegranate extracts

\begin{tabular}{lllll}
\hline \multicolumn{1}{c}{ PSO } & PJ & PP & PL \\
\hline IC50 & $229.38 \pm 2.66^{\mathrm{b}}$ & $181.52 \pm 8.56^{\mathrm{ab}}$ & $349.31 \pm 57.95^{\mathrm{C}}$ & $151.85 \pm 7.42^{\mathrm{a}}$ \\
\hline
\end{tabular}

Values represent mean \pm SD of replicate experiments $(n=3) .(p<0.05)$

identified by multiple comparisons across the six groups using least significant difference (LSD) procedures.

\section{Results}

\section{Polyphenol contents of pomegranate extracts}

The total phenols, Tanins, flavonoids, anthocyanins and total carotenoids content of pomegranate leaf, Juice and peel extracts in Tounsi variety were quantified. Results showed that Peel extract exhibited the highest content of phenols $(382 \pm 6.36 \mathrm{mg}$ GAE/g DW), carotenoids $(57.13 \pm 10.84 \mathrm{mg} / \mathrm{g} \mathrm{DW})$ and tannins $(68.33 \pm 0.87 \mathrm{mg}$ tannic acid/g DW). Leaves extract showed the highest amount of flavonoids $(54.84 \pm 0.58 \mathrm{mg}$ catechin $/ \mathrm{g} \mathrm{DW})$ and Juice extract was more concentrated in anthocyanins $(441.48 \pm 12.03 \mathrm{mg} / \mathrm{g} \mathrm{DW})$.

\section{Effect of PSO, PL, PJ and PP on AchE activity in vitro}

The ability of different pomegranate extracts to inhibit AchE was evaluated by the widely accepted modified Ellman's method and the results are summarized in the Table 1.

All the tested extracts inhibited the AchE in dose dependant manner. The comparison between IC50 values of different extracts revealed that leaves extracts displayed the highest inhibitory activity against AchE and it exhibited the lower IC50 value of $151.85 \mathrm{mg} / \mathrm{ml}$. Pomegranate juice was found to be the second stronger inhibitor with IC50 value of $181.52 \mathrm{mg} / \mathrm{ml}$ followed by PSO, which exhibited moderate AchE inhibition. However, pomegranate peel appears as the weakest inhibitor. The anti-cholinesterase activity of some pomegranate extracts was reported by previous studies $[40,41]$ but to the best of our knowledge, this is the first comparative study between different pomegranate parts on anticholinesterase activity.

\section{Effect of PSO, PL, PJ and PP on on BchE activity in brain of HFD-rats}

In order to determine effect of HFD regime and pomegranate consumption on BchE level in vivo, brain homogenate was assayed using the colorimetric method. As illustrated in Fig. 1, results showed that HFD regime increased BchE level in rat brain by $17.4 \%$ compared to control group. Administration of PSO, PL, PJ and PP to HDF-rats reduced brain BchE level respectively by $15.48 \%, 6.4 \%, 20 \%$ and $18.7 \%$ as compared to untreated HFD-rats but this reduction was not statistically significant.

\section{Effect of PSO, PL, PJ and PP on body and brain weights of HFD-rat}

Data in the Table 2 demonstrated that HFD diet induced a significant increase of body and brain weights respectively by $14.42 \%$ and $10.42 \%$ as compared to normal rats. However, the administration of PSO, PL, PJ and PP to HFD-rats decreased body weight respectively by $6 \%$, $10.44 \%, 7 \%$ and $9.4 \%$ and brain weight by $4.29 \%, 8 \%$, 9.2\% and $7.9 \%$ as compared to untreated HFD-rats.

Brain weight gain was corrected significantly only by pomegranate juice and pomegranate peel extract. However no corrective effect was observed in PSO and PL treated groups. So it is clear that HFD regime doesn't induce brain atrophy. Same finding was found in previous study about impact of grape seeds and skin extracts on brain lipotoxicity in rats fed HFD. In fact, they remarked that HFD increased brain weight and induced cholesterol and phospholipids accumulation [42].

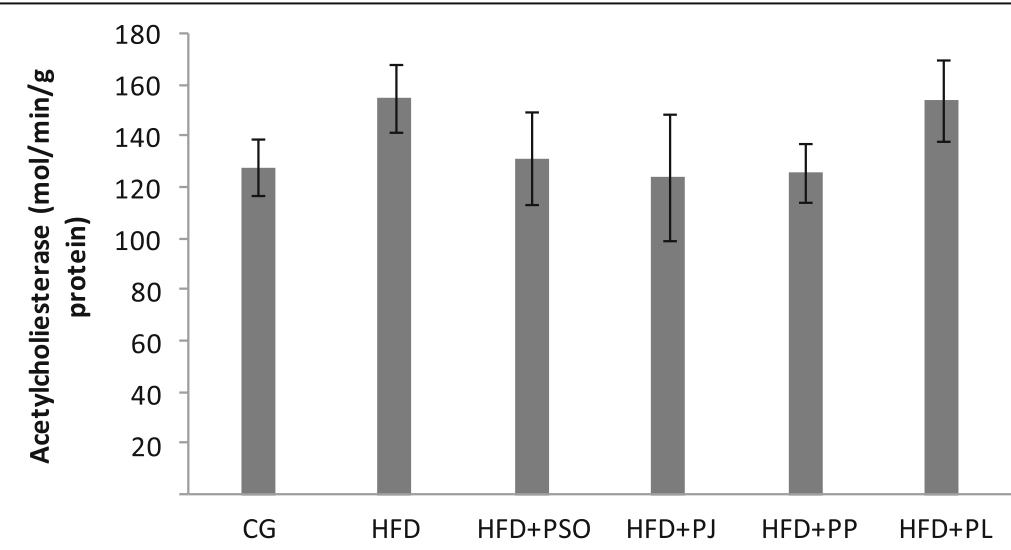

Fig. 1 Effect of different pomegranate parts on activity of Butyrylcholinesterase in HFD rat brain. Pomegranate seeds oil (PSO). Pomegranate Juice (PJ). Pomegranate Peel (PP) and Pomegranate Leaves (PL). No significant difference was recorded between all groups 
Table 2 Effects of pomegranate extracts on body and brain weight

\begin{tabular}{lllllll}
\hline & CG & HFD & HFD + PSO & HFD + PJ & HFD + PP & HFD + PL \\
\hline Start weight & $240.8 \pm 4.62$ & $236 \pm 7.03$ & $236.8 \pm 10.57$ & $239.6 \pm 4.02$ & $237.4 \pm 6.24$ & $237.8 \pm 8.7$ \\
End weight & $352.4 \pm 10.71$ & $411.8 \pm 6.01^{\mathrm{a}}$ & $387 \pm 5.56^{\mathrm{ab}}$ & $383 \pm 11.85^{\mathrm{ab}}$ & $372.8 \pm 4.6^{\mathrm{ab}}$ & $368.8 \pm 17.23^{\mathrm{ab}}$ \\
Brain weight & $1.46 \pm 0.04$ & $1.63 \pm 0.07^{\mathrm{a}}$ & $1.56 \pm 0.06$ & $1.48 \pm 0.12^{\mathrm{b}}$ & $1.50 \pm 0.07^{\mathrm{b}}$ & $1.5 \pm 0.02$ \\
\hline
\end{tabular}

Data are expressed as mean \pm SEM $(n=6) ;{ }^{a} p<0.05$ vs control group; ${ }^{\mathrm{b}} p<0.05$ vs HFD group

\section{Effect of PSO, PL, PJ and PP on lipid plasma profile and liver enzymes}

Results presented in Table 3 shows that HFD regime contributed to a significant elevation estimated by $50 \%$, $72 \%$ and $62 \%$ in respective lipid plasma parameters $\mathrm{CT}$, LDL-C and TG and a significant decrease in HDL-C level by $42 \%$, compared HFD groups to control groups. This result was confirmed by almost HFD regime studies which concluded that such regime clearly induced obesity characterized by body weight gain, disturbed plasma triglyceride, cholesterol, phospholipid, and abdominal fat accumulation [42].

We remarked that the four studied extracts have a significant corrective effect of LDL-C and TG levels compared to HFD group. In the case of HDL-C level, PJ and PSO treated groups presented a HDL-C level lower than that of HFD groups. This result indicated that dual PJ and PSO do not have a protective effect of HDL-C. Only PL exhibited a significant correction of HDL-C level estimated by $44 \%$ compared to HFD group.

For TC level, all pomegranate extracts decreased TC content when compared to HFD group but it is only significant in PP and PJ treated groups.

For the liver enzymes, we noted that HFD regime increased slightly AST level but did not affect ALT level compared to control groups. PP and PL extracts decreased significantly AST level against HFD group. This is can be explained by the hepato-protective effect of pomegranate peel and leaves. Some similar studies confirmed the same conclusion [30].

\section{Oxidative stress status}

Figures 2, 3, 4 and 5 depicted the effect of HFD regime and pomegranate extracts consumption in oxidative stress status in rat brain. MDA is a biomarker of oxidative stress and most studied in elevation of polyunsaturated fatty acid peroxidation [43] .As shown in Fig. 2, brain MDA level was $60 \%$ higher in HFD group than that of control group. All pomegranate extracts administration decreased significantly the level of MDA by $70 \%$ and $47 \%$ in respectively PL and PP treated groups and by $40 \%$ in dual PSO and PJ treated groups.

Furthermore, similar results were found for PC. In fact, as illustrated in Fig. 3, HFD regime increased PC level by $26 \%$ in rat brain of HFD group when compared to control group. However, the administration of pomegranate extracts restored PC level by reduction of $30 \%$ in all treated groups.

Brain SOD and GPx levels were affected also by HFD regime. In fact, as illustrated in Figs. 4 and 5, HFD group exhibited lower levels of SOD and GPx compared to that of control group. The reduction was estimated by $50 \%$. Consumption of PJ, PP and PL improved significantly levels of both enzymes compared to HFD group. However, No corrective effect was recorded to PSO.

\section{Discussion}

Our study which is the first study about the neuroprotective effect of pomegranate extracts on obese animal, shows that different pomegranate parts: leaves, juice, peel and seeds oil not only have a significant anti-obesity effect but also a neuroprotective potential on the development of diet-induced obesity.

$\mathrm{AChE}$ is an acetylcholine hydrolyzing enzyme that is responsible for the termination of cholinergic response. An increased AChE activity in brain provoked memory deficits as well as oxidative stress [44, 45]. In present study, HFD regime induced increase in AchE activity. This observation is confirmed in previous experiments

Table 3 Effects of pomegranate extracts on plasma lipid profile and liver enzyme content

\begin{tabular}{lllllll}
\hline Groups & GC & HFD & HFD + PSO & HFD + PJ & $H F D+P P$ & $H F D+P L$ \\
\hline TC (mmol/l) & $1.64 \pm 0.25$ & $3.28 \pm 0.33^{\mathrm{a}}$ & $2.49 \pm 0.43^{\mathrm{a}}$ & $2.18 \pm 0.73^{\mathrm{b}}$ & $2.01 \pm 0.71^{\mathrm{b}}$ & $2.58 \pm 0.79^{\mathrm{a}}$ \\
HDL (mmol/l) & $1.22 \pm 0.096$ & $0.7 \pm 0.4^{\mathrm{a}}$ & $0.58 \pm 0.19^{\mathrm{a}}$ & $0.64 \pm 0.32^{\mathrm{a}}$ & $0.89 \pm 0.32$ & $1.25 \pm 0.26^{\mathrm{b}}$ \\
LDL $(\mathrm{mmol} / \mathrm{l})$ & $0.63 \pm 0.26$ & $2.31 \pm 0.63^{\mathrm{a}}$ & $0.6 \pm 0.16^{\mathrm{b}}$ & $0.59 \pm 0.1^{\mathrm{b}}$ & $0.63 \pm 0.13^{\mathrm{b}}$ & $0.55 \pm 0.21^{\mathrm{b}}$ \\
TG $(\mathrm{mmol} / \mathrm{l})$ & $1.02 \pm 0.37$ & $2.74 \pm 0.41^{\mathrm{a}}$ & $1.22 \pm 0.3^{\mathrm{b}}$ & $1.23 \pm 0.58^{\mathrm{b}}$ & $1.05 \pm 0.59^{\mathrm{b}}$ & $0.94 \pm 0.32^{\mathrm{b}}$ \\
AST $(\mathrm{U} / \mathrm{l})$ & $121.6 \pm 14.01$ & $161.4 \pm 48.5$ & $120 \pm 11.74$ & $155.4 \pm 34$ & $109.4 \pm 28.48^{\mathrm{b}}$ & $111.8 \pm 45.04^{\mathrm{b}}$ \\
ALT $(\mathrm{U} / \mathrm{l})$ & $31.2 \pm 6.34$ & $32.6 \pm 7.73$ & $28.2 \pm 10.63$ & $29.8 \pm 11.6$ & $28.2 \pm 6.97$ & $29.8 \pm 8.04$ \\
\hline
\end{tabular}

Data are expressed as mean \pm SEM $(n=6){ }^{a} p<0.05$ vs control group; ${ }^{\mathrm{b}} p<0.05$ vs HFD group 


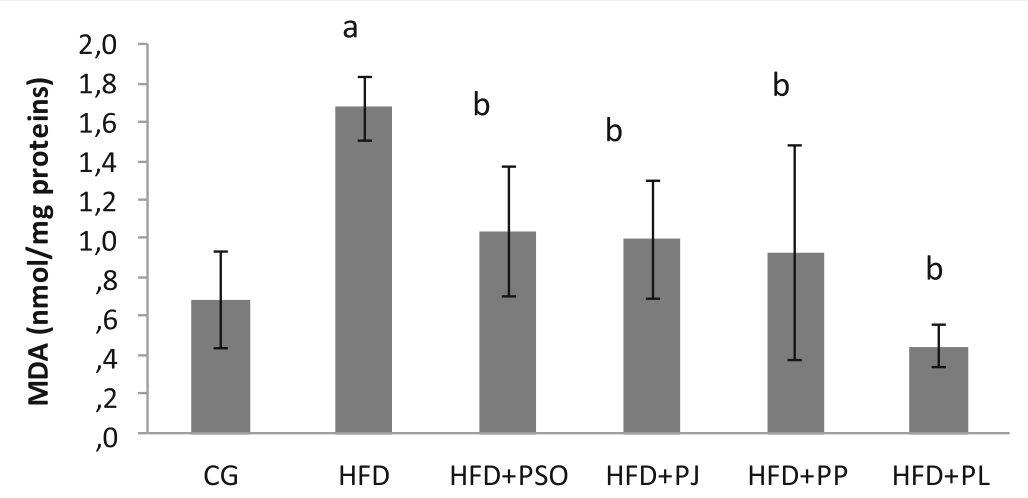

Fig. 2 Effect of different pomegranate parts on MDA activity in HFD rat brain. Pomegranate Seeds Oil (PSO). Pomegranate Juice (PJ). Pomegranate Peel (PP) and Pomegranate Leaves (PL). Results are expressed as mean \pm SEM. $(n=6) . P<0.05$ was considered significant. ${ }^{a}$ indicate significant difference compared to the values of CG. ${ }^{b}$ indicate significant difference compared to the values of HFD groups

$[42,46]$. However, long-term of pomegranate extracts consumption was found to reduce AChE activity. AChE activity depends largely on the membrane characteristics, since the enzyme is membrane bound. Increased activity of $\mathrm{AChE}$ is attributed to $\mathrm{Ca} 2+$ influx-mediated oxidative stress caused by Amyloid beta peptides. The mechanism of anticholinesterase activity of pomegranate may be due to antioxidant power of its bioactive compounds such as flavonoids. In fact, Ishige et al., found three distinct mechanisms of protection of neural cell from oxidative insults by flavonoids. These include preventing the influx of $\mathrm{Ca} 2+$ despite high levels of ROS, increasing intracellular GSH and directly lowering levels of ROS [47].

In addition, our results showed that oral administration of PJ and PP not only decreased body weight and improved lipids serum levels of HFD rats but also decreased significantly brain weight and attenuate brain oxidative stress by downregulating MDA and PC levels and upregulating SOD and GPx levels. Really, the antioxidant properties of pomegranate extracts have been well documented, which include free radical scavenging and inhibition of LPO as well as enhancement of antioxidant status and neuroprotection [48, 49]. Braidy et al. 2013 reported that PJ attenuate cytotoxicity and restore the redox imbalance caused by toxin treatment in Human Primary Neurons [18]. Subash et al. 2014 reported that diet supplemented by $4 \%$ of pomegranate extract attenuate oxidative damage in cortex and hippocampus by decrease in lipoperoxidation and protein carbonylation and restoration in the antioxidant enzymes level such as SOD, catalase (CAT), Glutathione peroxidase (GPx) and Glutathione (GSH) and inhibition of AchE activity [50]. Same findings were recorded also in others studies [51-53]. The neuroprotective effect of pomegranate peel and juice can be explained by their richness in bioactive compounds such as anthocyanins and tannins. In fact, Punicalagin (PG), a major compound in PJ and PP and widely known by power antioxidant activity was reported to have a potent neuroprotective effect against cerebral ischemia reperfusion

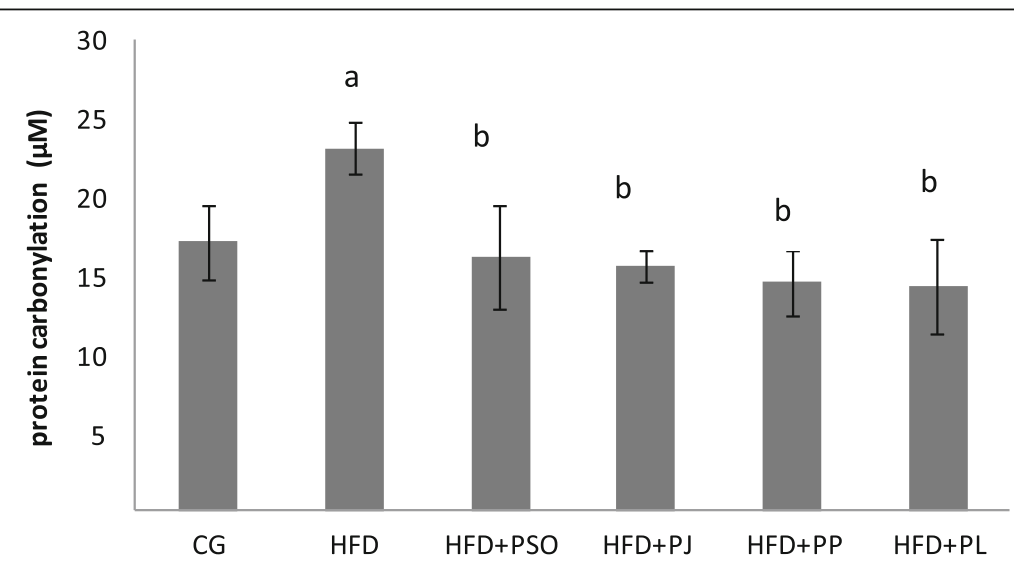

Fig. 3 Effect of different pomegranate parts on protein carbonylation in HFD rat brain. Pomegranate Seeds Oil (PSO). Pomegranate Juice (PJ). Pomegranate Peel (PP) and Pomegranate Leaves (PL). Results are expressed as mean \pm SEM. $(n=6)$. P $<0.05$ was considered significant. ${ }^{\text {a }}$ indicate significant difference compared to the values of CG. ${ }^{b}$ indicate significant difference compared to the values of HFD groups 


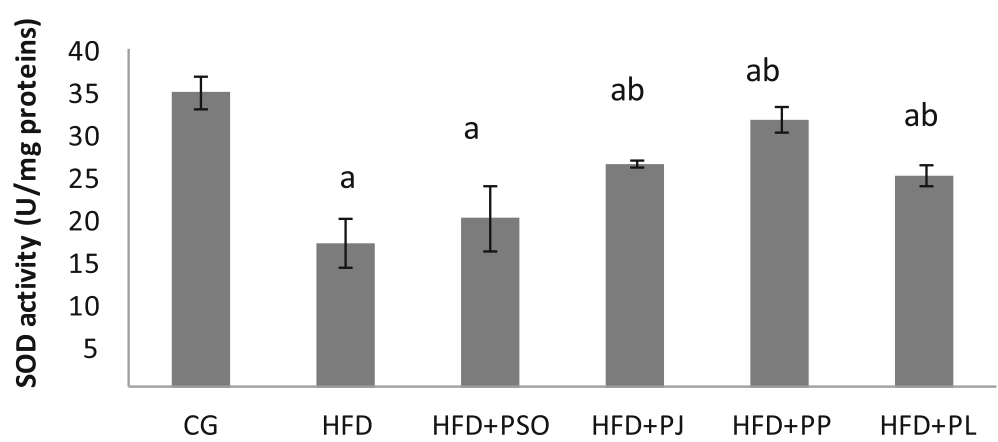

Fig. 4 Effect of different pomegranate parts on SOD activity in HFD rat brain. Pomegranate Seeds Oil (PSO). Pomegranate Juice (PJ). Pomegranate Peel (PP) and Pomegranate Leaves (PL). Results are expressed as mean \pm SEM. $(n=6) . P<0.05$ was considered significant. ${ }^{a}$ indicate significant difference compared to the values of CG. ${ }^{\text {b }}$ indicate significant difference compared to the values of HFD groups

induced oxidative brain injury in rats [54]. One of the possible mechanisms of neuroprotective effect of punicalagin was an improvement of $\mathrm{Na}+/ \mathrm{K}+$ ATPase activity, an integral membrane protein which maintains electrolyte and fluid balance in cells, organs, and the whole body [54]. ATPase is known to be highly susceptible to changes in the membrane lipids, which may be further attributed to the progressive increase in the Lipid peroxidation (LPO) products especially MDA levels $[55,56]$. Modification in $\mathrm{Na}+\mathrm{K}+-$ ATPase activity may induce neuronal death with features of both apoptosis and necrosis [57]. So a decrease in MDA level and membrane LPO by punicalagin can improve $\mathrm{Na}+\mathrm{K}+$ ATPase activity which drive the ion pumps to maintain neuron depolarization and thereby cellular integrity [54].

PSO is rich in polyunsaturated fatty acids, such as punicic acid, which is known to have hypolipidemic effect by suppression of TG synthesis in liver, through inhibition of fatty acid synthase [51]. In this study, PSO reduced significantly TG and LDL-C level but it hasn't any effect against HDL-C. Concerning brain parameters, results show that PSO inhibit significantly and in dose dependant manner in vitro human blood AchE activity, decreased slightly BchE activity in brain homogenate, and improved significantly brain oxidative status without any significant corrective effect on brain weight. The neuroprotective effect of PSO was confirmed previously following administration of Nano-PSO, a nanodroplet formulation of PSO, to mice suffering from neurodegenerative disease [58].

\section{Conclusion}

This study demonstrates that chronic intake of pomegranate extracts prevents against HFD complications such as hyperlipidemia and cerebral oxidative stress. In fact, the administration pomegranate juice, peel and seeds oil to HFD-fed rat deceased body weight, restored serum lipid levels, and attenuated oxidative stress in brain. All extracts showed significant inhibitory effect against human blood AchE activity in vitro study. An inhibitory effect against $\mathrm{BChE}$ in brain homogenate was also recorded after administration of different pomegranate extracts but this inhibition was statistically not significant. Taking into consideration all the demonstrated therapeutic effects of

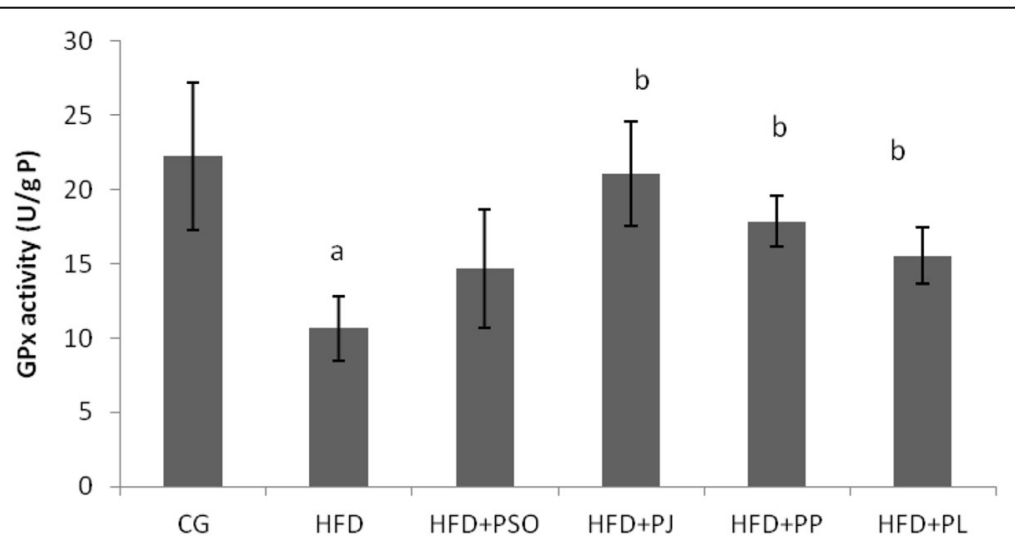

Fig. 5 Effect of different pomegranate parts on GPx activity in HFD rat brain. Pomegranate Seeds Oil (PSO). Pomegranate Juice (PJ). Pomegranate Peel (PP) and Pomegranate Leaves (PL). Results are expressed as mean \pm SEM. $(n=6) . P<0.05$ was considered significant. ${ }^{a}$ indicate significant difference compared to the values of CG. ${ }^{b}$ indicate significant difference compared to the values of HFD groups 
different pomegranate parts, this study underscores the neuroprotective potential of pomegranate fruits and encourages for further research to determine the bioactive mechanism.

\section{Abbreviations}

AchE: Acetylcholinesterace Enzyme; ALT: Alanine Aminotransferase: AST: Aspartate Aminotransferase; BchE: Butyrylcholinesterace Enzyme; BMI: Body Mass Index; BSA: Bovine serum albumin; BW: Body weight; CAT: Catalase; CG: Control group; DNPH: 2, 4, dinitrophenylhydrazine; DNTB: 5.5 5, 5'-Dithiobis 2-nitrobenzoic acid; GPx: Glutathione peroxidase; GSH: Glutathione; HDL-C: High density lipoprotein cholesterol; HFD: High fat high fructose diet; LDL-C: Low density lipoprotein cholesterol; MDA: Malondialdehyde; NBT: Nitroblue tetrazolum; PC: Protein carbonylation; PJ: Pomegranate juice; PL: Pomegranate leaves; PP: Pomegranate peel; PSO: Pomegranate seeds oil; PTCI: Propionylthiocholine iodide: ROS: Reactive Oxygen Species (ROS); SOD: Superoxide dismutase; TBARS: Thiobarbituric acid reactive substances; TC: Total cholesterol; TCA: Trichloroacetic acid; TG: Total triglycerides

\section{Acknowledgments}

The authors gratefully acknowledge the research facilities provided by CRDA Commissariat regional developpement agricole Monastir and the Ministry of Higher Education and Scientific Research (Tunisia).

\section{Funding}

Not applicable

\section{Availability of data and materials}

Data are all contained within the paper.

\section{Authors' contributions}

Zahra Amri designed and performed experiments, assembled the data and wrote the manuscript. Asma Ghorbel designed and assists in performing the cholinesterase activity. Mouna Turki designed and assists in performing lipid profile. Férièle Messadi Akrout gave the technical and conceptual advice. Fatma Ayadi gave the technical and conceptual advice. Abdelfateh Elfeki supervised the experimental work, gave the technical and conceptual advice Mohamed Hammami edited and approved the final version of manuscript. All authors read and approved the final manuscript.

\section{Ethics approval and consent to participate}

The experimental protocols and the handling of the animals were conducted in accordance with the guide for the care and use of laboratory animals issued by the University of Sfax, Tunisia and approved by the Tunisian Committee of Animal Ethics.

\section{Consent for publication}

Not Applicable.

\section{Competing interests}

The authors declare that they have no competing interests.

\section{Publisher's Note}

Springer Nature remains neutral with regard to jurisdictional claims in published maps and institutional affiliations.

\section{Author details}

'Biochemistry Laboratory, LR12ES05 "Nutrition- Functional Foods and vascular Health", Faculty of Medicine, University of Monastir, 5019 Monastir, Tunisia. 'Laboratoire d'Hygiène CHU Hédi Chaker, Sfax, Tunisia. ${ }^{3}$ Biochemistry Laboratory, CHU H. Bourguiba, Sfax, Tunisia. ${ }^{4}$ Laboratory of Animal Ecophysiology, Faculty of Sciences of Sfax, University of Sfax, Sfax, Tunisia.
Received: 11 December 2016 Accepted: 19 June 2017

Published online: 27 June 2017

\section{References}

1. Xu KZ-Y, Zhu C, Kim MS, Yamahara J, Li Y. Pomegranate flower ameliorates fatty liver in an animal model of type 2 diabetes and obesity. J Ethnopharmacol. 2009:123(2):280-7.

2. Loef M, Walach $\mathrm{H}$. Midlife obesity and dementia: meta-analysis and adjusted forecast of dementia prevalence in the united states and china. Obesity. 2013;21(1):E51-5.

3. Anstey $\mathrm{K}$, Cherbuin N, Budge M, Young J. Body mass index in midlife and late-life as a risk factor for dementia: a meta-analysis of prospective studies. Obes Rev. 2011;12(5):e426-37.

4. Arnoldussen IA, Kiliaan AJ, Gustafson DR. Obesity and dementia: adipokines interact with the brain. Eur Neuropsychopharmacol. 2014;24(12):1982-99.

5. Albert MS, DeKosky ST, Dickson D, Dubois B, Feldman HH, Fox NC, et al. The diagnosis of mild cognitive impairment due to Alzheimer's disease: recommendations from the National Institute on Aging-Alzheimer's association workgroups on diagnostic guidelines for Alzheimer's disease. Alzheimers Dement. 2011:7(3):270-9.

6. Pistell PJ, Morrison CD, Gupta S, Knight AG, Keller JN, Ingram DK, et al. Cognitive impairment following high fat diet consumption is associated with brain inflammation. J Neuroimmunol. 2010;219(1-2):25-32.

7. Ward MA, Carlsson CM, Trivedi MA, Sager MA, Johnson SC. The effect of body mass index on global brain volume in middle-aged adults: a cross sectional study. BMC Neurol. 2005:5(1):1.

8. Whitmer RA, Gunderson EP, Quesenberry CP, Zhou J, Yaffe K. Body mass index in midlife and risk of Alzheimer disease and vascular dementia. Curr Alzheimer Res. 2007;4(2):103-9.

9. Kivipelto M, Ngandu T, Fratiglioni L, Viitanen $M$, Kåreholt I, Winblad B, et al. Obesity and vascular risk factors at midlife and the risk of dementia and Alzheimer disease. Arch Neurol. 2005;62(10):1556-60.

10. Gustafson D, Bäckman K, Waern M, Östling S, Guo X, Zandi P, et al. Adiposity indicators and dementia over 32 years in Sweden. Neurology. 2009:73(19):1559-66.

11. Waldstein S, Katzel L. Interactive relations of central versus total obesity and blood pressure to cognitive function. Int J Obes. 2006;30(1):201-7.

12. Pannacciulli N, Del Parigi A, Chen K, Le DSN, Reiman EM, Tataranni PA. Brain abnormalities in human obesity: a voxel-based morphometric study. Neurolmage. 2006;31(4):1419-25

13. Businaro R, Ippoliti F, Ricci S, Canitano N, Fuso A. Alzheimer's disease promotion by obesity: induced mechanisms-molecular links and perspectives. Current gerontology and geriatrics research. 2012;2012

14. Delgado TC, Violante IR, Nieto-Charques L, Cerdán S. Neuroglial metabolic compartmentation underlying leptin deficiency in the obese ob/ob mice as detected by magnetic resonance imaging and spectroscopy methods. J Cereb Blood Flow Metab. 2011;31(12):2257-66.

15. Chattipakorn S, Pongpanparadorn A, Pratchayasakul W, Pongchaidacha A, Ingkaninan K, Chattipakorn N. Tabernaemontana divaricata Extract inhibits neuronal acetylcholinesterase activity in rats. J Ethnopharmacol. 2007;110(1):61-8.

16. Bonfleur M, Brito N, Grassiolli S, Mathias PCF, Silva ACM, Balbo S. Altered brain acetylcholinesterase activity in MSG-induced obese rats. Diabetes research. 2000;35(1):27-32.

17. Zhang X, Dong F, Ren J, Driscoll MJ, Culver B. High dietary fat induces NADPH oxidase-associated oxidative stress and inflammation in rat cerebral cortex. Exp Neurol. 2005;191(2):318-25.

18. Braidy N, Selvaraju S, Essa MM, Vaishnav R, Al-Adawi S, Al-Asmi A, et al. Abd Alrahman Alobaidy A, Lakhtakia R. Guillemin GJ: Neuroprotective effects of a variety of pomegranate juice extracts against MPTP-induced cytotoxicity and oxidative stress in human primary neurons Oxidative medicine and cellular longevity. 2013;2013

19. Devore EE, Grodstein F, van Rooij FA, et al. Dietary antioxidants and longterm risk of dementia. Arch Neurol. 2010;67(7):819-25.

20. Galasko DR, Peskind E, Clark CM, et al. Antioxidants for alzheimer disease: a randomized clinical trial with cerebrospinal fluid biomarker measures. Arch Neurol. 2012:69(7):836-41.

21. Calabrese V, Cornelius C, Mancuso C, Barone E, Calafato S, Bates T, et al. Vitagenes, dietary antioxidants and neuroprotection in neurodegenerative diseases. Front Biosci. 2009;14(3):76-97. 
22. Johanningsmeier SD, Harris GK. Pomegranate as a functional food and nutraceutical source. Annu Rev Food Sci Technol. 2011;2:181-201.

23. Pérez-Vicente A, Gil-Izquierdo A, García-Viguera C. In vitro gastrointestinal digestion study of pomegranate juice phenolic compounds, anthocyanins, and vitamin C. J Agric Food Chem. 2002;50(8):2308-12.

24. Gil Ml, Tomás-Barberán FA, Hess-Pierce B, Holcroft DM, Kader AA. Antioxidant activity of pomegranate juice and its relationship with phenolic composition and processing. J Agric Food Chem. 2000;48(10):4581-9.

25. Aviram M, Volkova N, Coleman R, Dreher M, Reddy MK, Ferreira D, et al. Pomegranate Phenolics from the peels, arils, and flowers are Antiatherogenic: studies in vivo in atherosclerotic apolipoprotein E-deficient (E0) mice and in vitro in cultured macrophages and lipoproteins. J Agric Food Chem. 2008;56(3):1148-57.

26. Lei F, Zhang XN, Wang W, Xing DM, Xie WD, Su H, et al. Evidence of antiobesity effects of the pomegranate leaf extract in high-fat diet induced obese mice. Int J Obes. 2007;31(6):1023-9.

27. Kim ND, Mehta R, Yu W, Neeman I, Livney T, Amichay A, et al. Chemopreventive and adjuvant therapeutic potential of pomegranate (Punica granatum) for human breast cancer. Breast Cancer Res Treat. 2002; 71(3):203-17.

28. Hartman RE, Shah A, Fagan AM, Schwetye KE, Parsadanian M, Schulman RN, et al. Pomegranate juice decreases amyloid load and improves behavior in a mouse model of Alzheimer's disease. Neurobiol Dis. 2006;24(3):506-15.

29. Zou X, Yan C, Shi Y, Cao K, Xu J, Wang X, et al. Mitochondrial dysfunction in obesity-associated nonalcoholic fatty liver disease: the protective effects of pomegranate with its active component punicalagin. Antioxid Redox Signal. 2014;21(11):1557-70.

30. Harzallah A, Hammami M, Kępczyńska MA, Hislop DC, Arch JR, Cawthorne MA, et al. Comparison of potential preventive effects of pomegranate flower, peel and seed oil on insulin resistance and inflammation in high-fat and high-sucrose diet-induced obesity mice model. Arch Physiol Biochem. 2016;122(2):75-87.

31. Vroegrijk IOCM, van Diepen JA, van den Berg S, Westbroek I, Keizer H, Gambelli $L$, et al. Pomegranate seed oil, a rich source of punicic acid, prevents diet-induced obesity and insulin resistance in mice. Food Chem Toxicol. 2011;49(6):1426-30

32. Cao K, Xu J, Pu W, Dong Z, Sun L, Zang W, et al. Punicalagin, an active component in pomegranate, ameliorates cardiac mitochondrial impairment in obese rats via AMPK activation. Sci Rep. 2015;5:14014.

33. Rodriguez J, Gilson H, Jamart C, Naslain D, Pierre N, Deldicque L, et al. Pomegranate and green tea extracts protect against ER stress induced by a high-fat diet in skeletal muscle of mice. Eur J Nutr. 2015;54(3):377-89.

34. Choi HY, Jhun EJ, Lim BO, Chung IM, Kyung SH, Park DK. Application of flow injection-chemiluminescence to the study of radical scavenging activity in plants. Phytother Res. 2000;14(4):250-3.

35. Doctor B, Toker L, Roth E, Silman I. Microtiter assay for acetylcholinesterase Anal Biochem. 1987;166(2):399-403.

36. Draper H. Hadley M: [43] malondialdehyde determination as index of lipid peroxidation. Methods Enzymol. 1990;186:421-31.

37. Levine R: Determination of carbonyl content in oxidatively modified proteins/Levine RL, Garland D., Oliver CN, Amici A., Climent I., Lenz A.-G. , Ahn B.-W., Shaltiel S., Stadtman ER. Methods in Enzymolology-1990186-P:465-478.

38. Sun Y, Oberley LW, Li Y. A simple method for clinical assay of superoxide dismutase. Clin Chem. 1988;34(3):497-500.

39. Flohe L, Gunzler WA. Assays of glutathione peroxidase. Methods Enzymol. 1984;105:114-21.

40. Mathew M, Subramanian S. In vitro screening for anti-cholinesterase and antioxidant activity of methanolic extracts of ayurvedic medicinal plants used for cognitive disorders. PLoS One. 2014;9(1):e86804.

41. Bekir J, Mars M, Souchard JP, Bouajila J. Assessment of antioxidant, antiinflammatory, anti-cholinesterase and cytotoxic activities of pomegranate (Punica granatum) leaves. Food Chem Toxicol. 2013;55:470-5.

42. Charradi K, Sebai H, Elkahoui S, Hassine FB, Limam F, Aouani E. Grape seed extract alleviates high-fat diet-induced obesity and heart dysfunction by preventing cardiac siderosis. Cardiovasc Toxicol. 2011;11(1):28-37.

43. Nasri R, Abdelhedi O, Jemil I, Daoued I, Hamden K, Kallel C, et al. Ameliorating effects of goby fish protein hydrolysates on high-fat-highfructose diet-induced hyperglycemia, oxidative stress and deterioration of kidney function in rats. Chem Biol Interact. 2015;242:71-80.
44. Melo JB, Agostinho P, Oliveira CR. Involvement of oxidative stress in the enhancement of acetylcholinesterase activity induced by amyloid betapeptide. Neurosci Res. 2003;45(1):117-27.

45. Schallreuter KU, Elwary SMA, Gibbons NCJ, Rokos H, Wood JM. Activation/ deactivation of acetylcholinesterase by $\mathrm{H} 2 \mathrm{O} 2$ : more evidence for oxidative stress in vitiligo. Biochem Biophys Res Commun. 2004;315(2):502-8.

46. Paes AM, Carniatto SR, Francisco FA, Brito NA, Mathias PC. Acetylcholinesterase activity changes on visceral organs of $\mathrm{VMH}$ lesion-induced obese rats. The International journal of neuroscience. 2006;116(11):1295-302.

47. Ishige K, Schubert D, Sagara Y. Flavonoids protect neuronal cells from oxidative stress by three distinct mechanisms. Free Radic Biol Med. 2001; 30(4):433-46.

48. Jing $P$, Ye $T$, Shi $H$, Sheng $Y$, Slavin M, Gao B, et al. Antioxidant properties and phytochemical composition of China-grown pomegranate seeds. Food Chem. 2012;132(3):1457-64.

49. Tezcan F, Gültekin-Özgüven M, Diken T, Özçelik B, Erim FB. Antioxidant activity and total phenolic, organic acid and sugar content in commercial pomegranate juices. Food Chem. 2009;115(3):873-7.

50. Subash S, Essa MM, Al-Asmi A, Al-Adawi S, Vaishnav R, Braidy N, et al. Pomegranate from Oman alleviates the brain oxidative damage in transgenic mouse model of Alzheimer's disease. Journal of Traditional and Complementary Medicine. 2014:4(4):232-8.

51. Arao K, Yotsumoto H, Han S-Y, Nagao K, Yanagita T. The 9cis,11trans,13cis isomer of conjugated linolenic acid reduces apolipoprotein B100 secretion and triacylglycerol synthesis in HepG2 cells. Biosci Biotechnol Biochem. 2004;68(12):2643-5.

52. Ahmed MAE, El Morsy EM, Ahmed AAE. Pomegranate extract protects against cerebral ischemia/reperfusion injury and preserves brain DNA integrity in rats. Life Sci. 2014;110(2):61-9.

53. Moneim AEA. Antioxidant activities of Punica granatum (pomegranate) peel extract on brain of rats. Journal of Medicinal Plants Research. 2012;6(2):195-9.

54. Yaidikar L, Byna B, Thakur SR. Neuroprotective effect of punicalagin against cerebral ischemia reperfusion-induced oxidative brain injury in rats. J Stroke Cerebrovasc Dis. 2014;23(10):2869-78

55. Rauchova H, Ledvinkova J, Kalous M, Drahota Z. The effect of lipid peroxidation on the activity of various membrane-bound ATPases in rat kidney, Int J Biochem Cell Biol. 1995:27(3):251-5.

56. Dobrota D, Matejovicova M, Kurella EG, Boldyrev AA. Na/K-ATPase under oxidative stress: molecular mechanisms of injury. Cell Mol Neurobiol. 1999. 19(1):141-9.

57. Lees AJ. Dopamine agonists in Parkinson's disease: a look at apomorphine. Fundamental \& clinical pharmacology. 1993;7(3-4):121-8.

58. Mizrahi M, Friedman-Levi Y, Larush L, Frid K, Binyamin O, Dori D, et al. Pomegranate seed oil nanoemulsions for the prevention and treatment of neurodegenerative diseases: the case of genetic CJD. Nanomedicine. 2014; 10(6):1353-63.

\section{Submit your next manuscript to BioMed Central and we will help you at every step:}

- We accept pre-submission inquiries

- Our selector tool helps you to find the most relevant journal

- We provide round the clock customer support

- Convenient online submission

- Thorough peer review

- Inclusion in PubMed and all major indexing services

- Maximum visibility for your research

Submit your manuscript at www.biomedcentral.com/submit

) Biomed Central 